doctors with domestic commitments and the role of ethics in psychiatry. The CTC led the way with its working party reports on the training of psychiatrists in Europe, and the College is now involved in setting up a European conference scheduled for 1992.

To the best of our knowledge this is the only committee in the College that takes women's issues seriously and has the subject as a standing item on the agenda. We are moving forward slowly but surely, and we ask of our colleagues - senior and junior - to support us when we are right and to correct us if we are not. The CTC cannot be a constant pain simply because the habituation response would decrease its value. An occasional irregular jolt is more likely to keep the College on its toes.

Collegiate Trainees' Committee

Dinesh BHUGRA

Amanda POYnTON

Ola Junaid

Royal College of Psychiatrists

17 Belgrave Square

London SWIX 8 PG

\section{British Neuropsychiatry Association}

SIR: Dening (Journal, June 1990, 156, 915), in his review of essential reading in the field of 'organic psychiatry', is kind enough to suggest that psychiatric trainees should consider joining the British Neuropsychiatry Association. We, the committee of that Association, are indeed keen to encourage all interested trainees to join. The British Neuropsychiatry Association (BNPA) was formed in 1988 in order to encourage cross-disciplinary discussion in the fields of neuropsychiatry, neurology, neuropsychology and allied basic sciences. So far, we have held meetings twice each year, each of which have concentrated on the neuropsychiatry of some particular topic, such as the frontal lobes, movement disorders, dementia and emotion. Speakers have always come from a wide range of neuropsychiatric and allied disciplines, and we encourage interesting case and video presentations, particularly by trainees. It has generally been agreed that our meetings are lively, varied and interesting.

Membership of the Association costs $£ 15.00$ per annum and attendance at our meetings is free to members. If trainees (or any other psychiatrists) are interested, then we hope that they will feel free to contact any member of the committee for further information. In particular they should contact the Honorary Secretary, Dr J. M. Bird, Consultant Neuropsychiatrist, Burden Neurological Hospital,
Stoke Lane, Stapleton, Bristol BS16 1QT. (Tel: (0272) 701212 ext. 2925).

\author{
W. A. Lishman \\ J. M. BIRD \\ M. ROBERTSON \\ E. H. REYNOLDS \\ M. WYKE \\ M. A. RoN
}

The British Neuropsychiatry Association

\section{The Bowdlerisation of psychiatry}

SIR: Lewis and his colleagues have recently published two articles in the Journal based on postal surveys of psychiatrists' responses to case vignettes. These reports show disturbingstereotyping by psychiatrists.

In the first article (Lewis \& Appleby; Journal, July $1988,153,44-49$ ), perjorative judgements turning on the previous diagnosis of a personality disorder were used to argue that the concept of personality disorder "should be abandoned". In the recent article (Lewis et al; Journal, September 1990, 157, 410-415) entitled "Are British psychiatrists racist?", essentially similar results, turning on the words 'white' versus 'AfroCaribbean', lead them to suggest that the concept of racism be avoided and that of 'race thinking' be substituted. Abandoning the concept of 'black' would be more consistent but more problematic.

In the latest article (paragraphs $2 \& 3$, p. 415) Dr Lewis et al suggest that the "professional literature and training", in particular their own contribution to the former, may prevent prejudice "by highlighting the nature of this stereotype". We wonder about their understanding of the word 'highlighting'.

Tomas Bowdler, MD (1754-1825), published his Family Shakespeare in 1818. It was an "expurgated edition". He went on, perhaps less influentially, to remove all sexual references from Gibbon's Decline and Fall of the Roman Empire. Lewis and his colleagues suggest a similar semantic purification of the psychiatric literature, but their Bowdlerisations are neither consistent nor a profitable solution. To remove or tone down words is not to 'highlight' stereotypes and their dangers. Perhaps caring professionals find it as painful to acknowledge their prejudices and unconscious racism as the Victorians found it to acknowledge sexual intercourse.

Dr Lewis et al suggest that accusations of racism "seldom change beliefs or behaviour for the better", but neither will abandoning terms nor the use of comfortable phrases like 'race thinking'. These strategies do not expunge the obnoxious attitudes. A sample of British psychiatrists would more often expect an Afro-Caribbean patient to be violent than 